\title{
ПРАКТИЧЕСКИЕ АСПЕКТЫ ФОРМИРОВАНИЯ СТРАТЕГИИ ЭКОНОМИЧЕСКОЙ БЕЗОПАСНОСТИ КОМПАНИЙ НЕФТЕГАЗОВОЙ ОТРАСЛИ
}

\author{
(ㄷ) 2021 Ячменева Е.Д. \\ Санкт-Петербургский политехнический университет Петра Великого, Россия, Санкт-Петербург \\ E-mail: katja-jachmeneva0@mail.ru \\ (c) 2021 Дуболазова Ю.А. \\ Санкт-Петербургский политехнический университет Петра Великого, Россия, Санкт-Петербург \\ E-mail: dubolazova_yua@spbstu.ru
}

(c) 2021 Замбржицкая Е.C.

Магнитогорский государственный технический университет им. Г.И.Носова, Россия, Магнитогорск

E-mail: jenia-v@yandex.ru

Настоящая научно-исследовательская статья посвящена вопросу обоснования теоретической и практической целесообразности формирования и реализации стратегии экономической безопасности современных компаний, занятых в нефтегазовой отрасли. Центральное место в проведенном исследовании занимает теоретический анализ наиболее распространенных подходов к пониманию сущности как экономической безопасности хозяйствующего субъекта в целом, так и стратегии экономической безопасности компании в частности, а также проведен детальный разбор основных структурных элементов данных понятий. В рассматриваемой научно-исследовательской статье также освещен вопрос обоснования организационно-методических положений по разработке и реализации стратегии обеспечения экономической безопасности компании с использованием современных подходов и процедур. Авторами разобрана и описана содержательная характеристика стратегии экономической безопасности, поскольку она является важнейшим структурным элементом системы экономической безопасности любой современной компании. По результатам выполненного в рамках настоящего исследования теоретико-методического анализа существующих подходов к формированию стратегии экономической безопасности, а также анализа практического опыта лидирующих компаний нефтегазового сектора (в частности, ПАО «Лукойл») были смоделированы принципиальные основы алгоритма построения стратегии экономической безопасности типовой нефтеперерабатывающей компании, функционирующей на территории РФ.

Ключевые слова: экономическая безопасность, стратегия, система, предприятия нефтегазового сектора, алгоритм, проектирование, угрозы, предотвращение, мероприятия, эффективность, управленческие решения.

Введение Вопрос обеспечения экономической безопасности активно обсуждается на всех уровнях как в теории, так и на практике. Однако, несмотря на его значимость, не существует единого общепризнанного подхода к определению как самого понятия «экономическая безопасность», так и производного от него понятия «экономическая безопасность компании».

Важно отметить, что само по себе понятие «экономическая безопасность» рассматривается применительно к нескольким уровням хозяйствования, а именно:

- экономическая безопасность страны;

- экономическая безопасность региона;

- экономическая безопасность отрасли национальной экономики;
- экономическая безопасность предприятия.

В рамках настоящей статьи основное внимание будет уделено исключительно экономической безопасности предприятий, причем с определенной отраслевой принадлежностью, а именно предприятиям нефтегазовой отрасли.

Цель исследования Цель данного исследования - развитие теоретико-методологических основ для разработки стратегии экономической безопасности современных компаний, занятых нефтегазовой отрасли.

Материалы и методы исследования При выполнении настоящего исследования использовались следующие методы: теоретический анализ и обобщение научной литературы, пери- 
одических изданий по вопросу формирования стратегии экономической безопасности предприятий нефтегазового сектора экономики РФ.

Важно отметить, что вопрос экономической безопасности нефтеперерабатывающих компаний является коммерческой тайной и выводы, представленные далее по тексту настоящей статьи, были сформированы исключительно на основе анализа публичных источников информации (в частности, интернет-ресурсы, публичная отчетность и т.д.).

Результаты исследования и их обсуждение В настоящее время существует определенная вариативность термина «экономическая безопасность предприятия / компании / фирмы / организации». Для корректного использования исследуемого термина в рамках дальнейшего исследования рассмотрим основные из существующих подходов к определению его сущности.

Проанализировав ряд источников, а также практическую составляющую, можно сделать вывод, что большинство ведущих авторов придерживаются подходов, которые условно можно сгруппировать в три группы:

- ресурсно-функциональный;

- подход на основе угроз;

- смешанный (комбинированный).

Рассмотрим каждый из них более детально.

Е.А. Олейников， Е.В.Лотова， Н.В. Матвеев являются представителями первого подхода. В своем подходе авторы основываются на поня- тиях эффективного функционирования, сбалансированности, развития и достижения стратегических целей компании за счет эффективного использования всех видов ресурсов.

Согласно данному подходу, экономическая безопасность базируется на интеллектуально-кадровых, финансовых, социально-экономических, информационных и технико-технологических ресурсах. По мнению сторонников данного подхода, экономическая безопасность в первую очередь создает (определяет) конкурентоспособную среду, тем самым обеспечивая эффективность деятельности компании.

Далее рассмотрим второй подход. О.В.Климочкин, А.М. Арипшев, В.К. Сенчагов, М.Бендиков, Л. А. Запорожцева, 3. С. Варналий подходят к определению исследуемого термина через понятие угроз и мер защиты от них.

В целом, предполагается, что угроза подразумевает условия и факторы, способные нанести вред и нарушить безопасность хозяйствующего объекта.

Следуя данному подходу, экономическая безопасность компании трактуется как способность оперативного противостояния внутренним и внешним угрозам и адаптацию к быстроизменяющимся условиям.

Угрозы экономической безопасности компании можно идентифицировать по различным критериям:

- источник возникновения угрозы

- природа возникновения угроз;

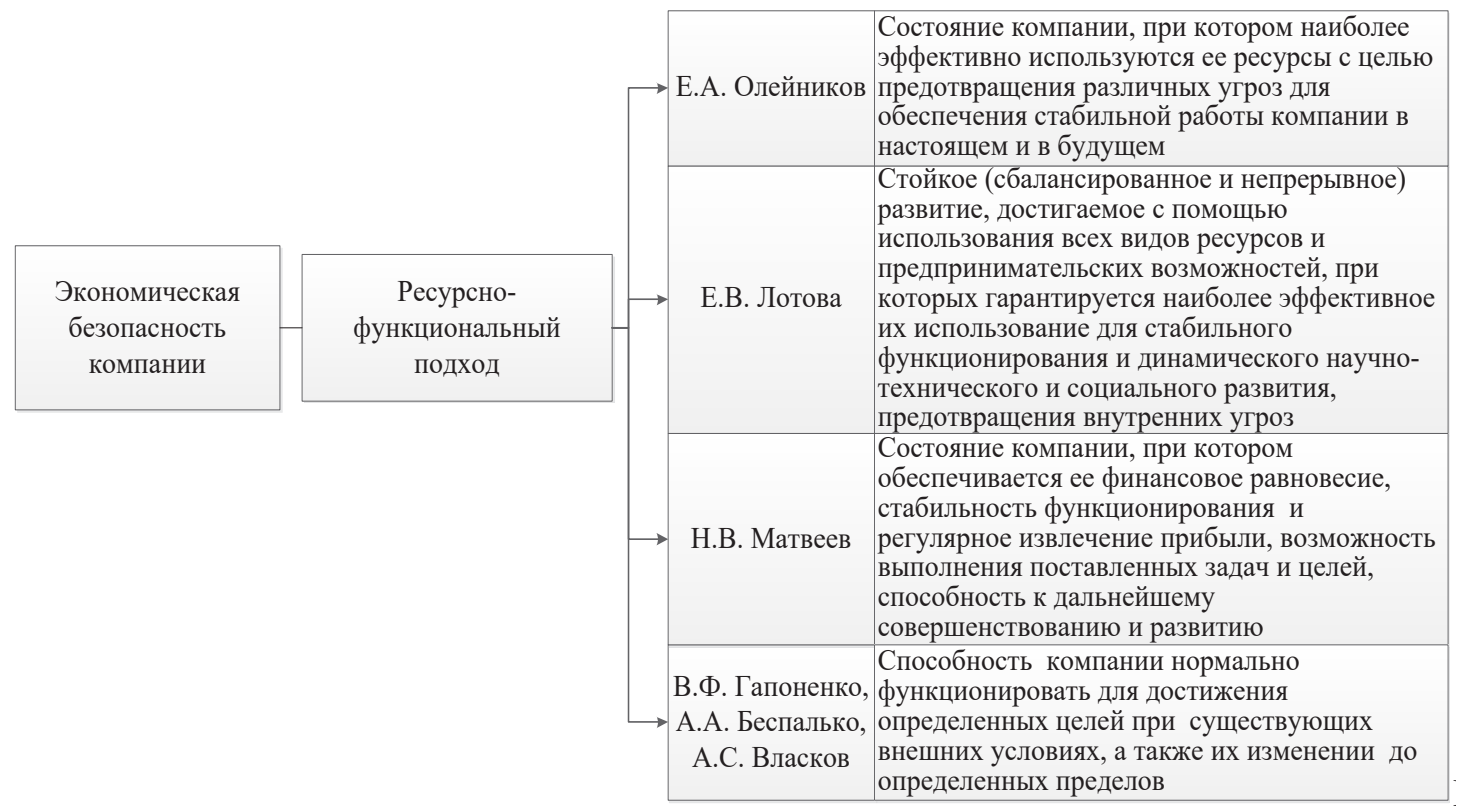

Рисунок 1. Ресурсно-функциональный подход к рассмотрению понятия «экономическая безопасность предприятия» 
- вероятность наступления;

- объект посягательства;

- возможность прогнозирования и предотвращения;

- последствия угроз;

- размер ущерба.

Анализ определений авторов, являющихся сторонниками второго подхода к определению сущности понятия «экономическая безопасность компании», представлен на рисунке 2.

Важно отметить, что указанный подход, то есть подход к определению понятия экономической безопасности через противодействие угрозам, является наиболее распространенным на практике, так именно данная идеология является понятной для большинства менеджеров крупных компаний и легко ими интерпретируется в различные управленческие инструменты.

В настоящее существуют сторонники третьего подхода к пониманию сущности понятия «экономическая безопасность компании», объединяющие ресурсно-функциональный и подход на основе угроз. Суть указанного подхода с позиции ведущих представителей представлена на рисунке 3.

Суть третьего подхода сводится к тому, что экономическая безопасность компании есть некая система противодействия негативным воздействиям, в условиях функционирования которой ничего не угрожают нормальному функционированию компании и не препятствует достижению ее стратегических целей, т.е. система экономической безопасности компании нацелена на достижение целей компании в условиях жесткой конкуренции и хозяйственного риска.

Таким образом, каждый автор или группа авторов конкретизируют и выделяют наиболее значимые смысловые части в подходах к понятию «экономическая безопасность компании». Конечно же, некоторые подходы к данному понятию сужены и сводятся к принципам эффективности и управления компанией. Проанализировав три подхода к сущности экономической безопасности компании, наиболее общим и рациональным выступает - смешанный (комбинированный) подход. Достаточно удачно сущность данного понятия прослеживается в формулировках Г.В. Козаченко и В.П.Пономарева, а также Е.В.Раздиной, отсюда напрашивается вывод, что, в первую очередь экономическая безопасность компании - это комплекс мер, который способствуют повышению финансовой устойчивости компании, в том числе одна

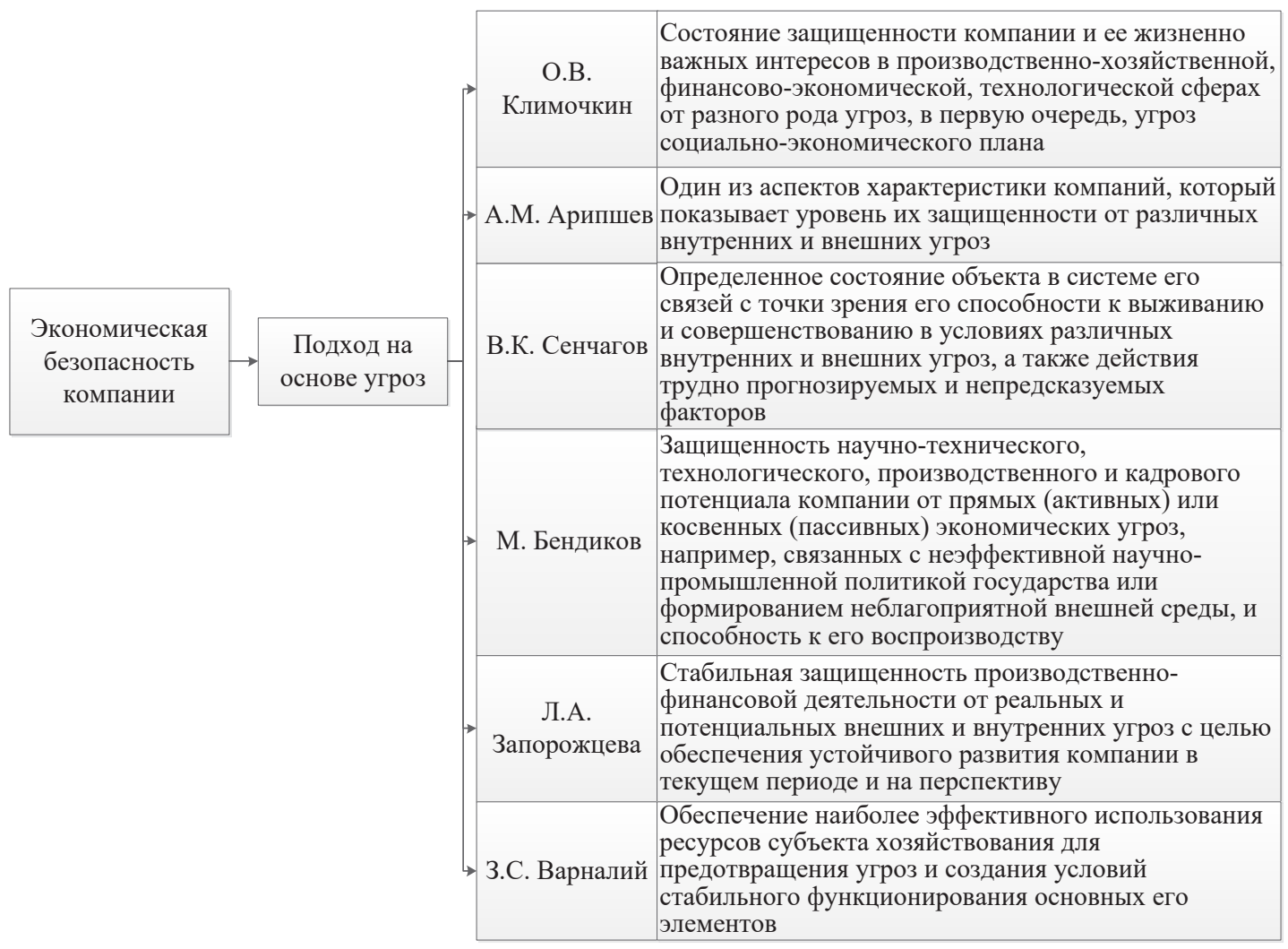

Рисунок 2. Подход на основе угроз к рассмотрению понятия «экономическая безопасность предприятия» 


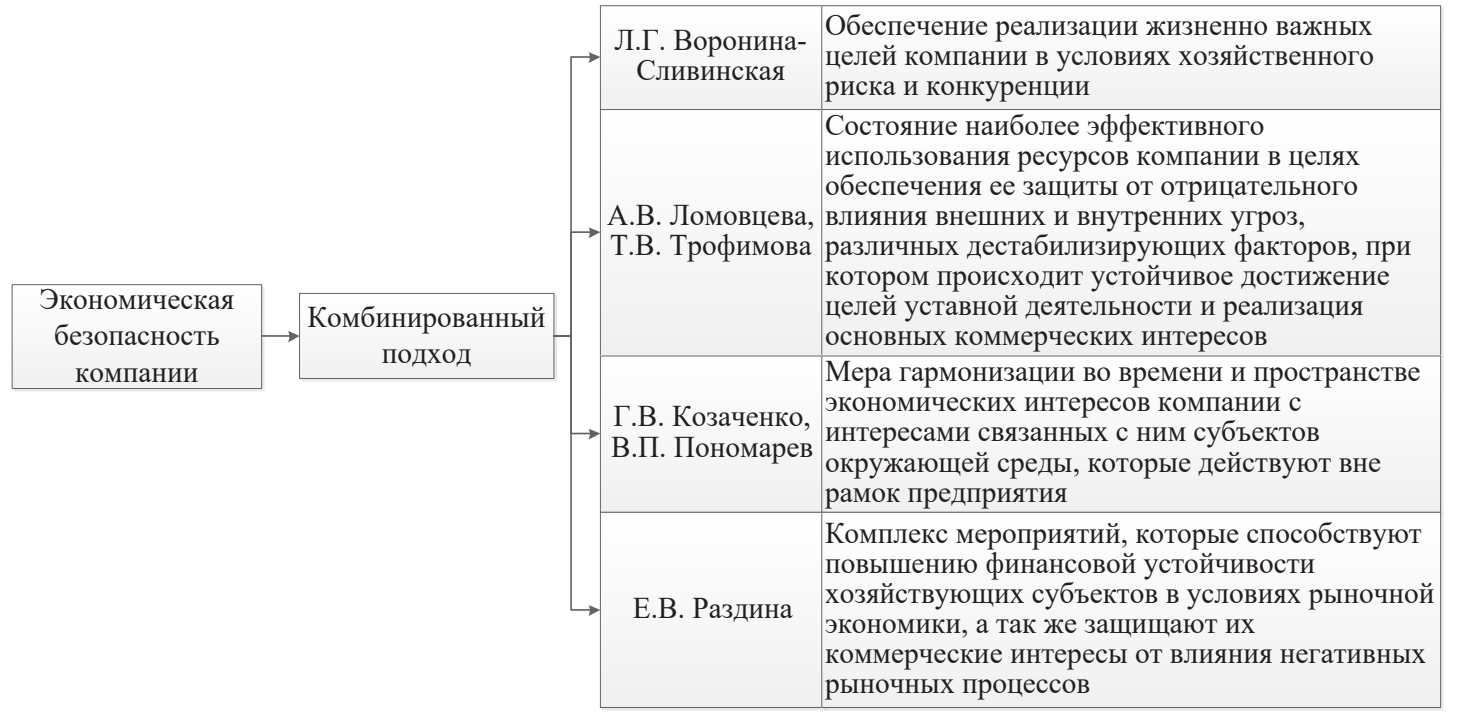

Рисунок 3. Смешанный (комбинированный) подход к определению понятия «экономическая безопасность компании»

из мер - это гармонизация во времени и пространстве экономических интересов компании с интересами связанных с ней экономических субъектов. Именно данное определение предлагается принять в качестве основного для целей дальнейшего изложения материала настоящей статьи.

Следующим принципиальным моментом является понимание того факта, что система

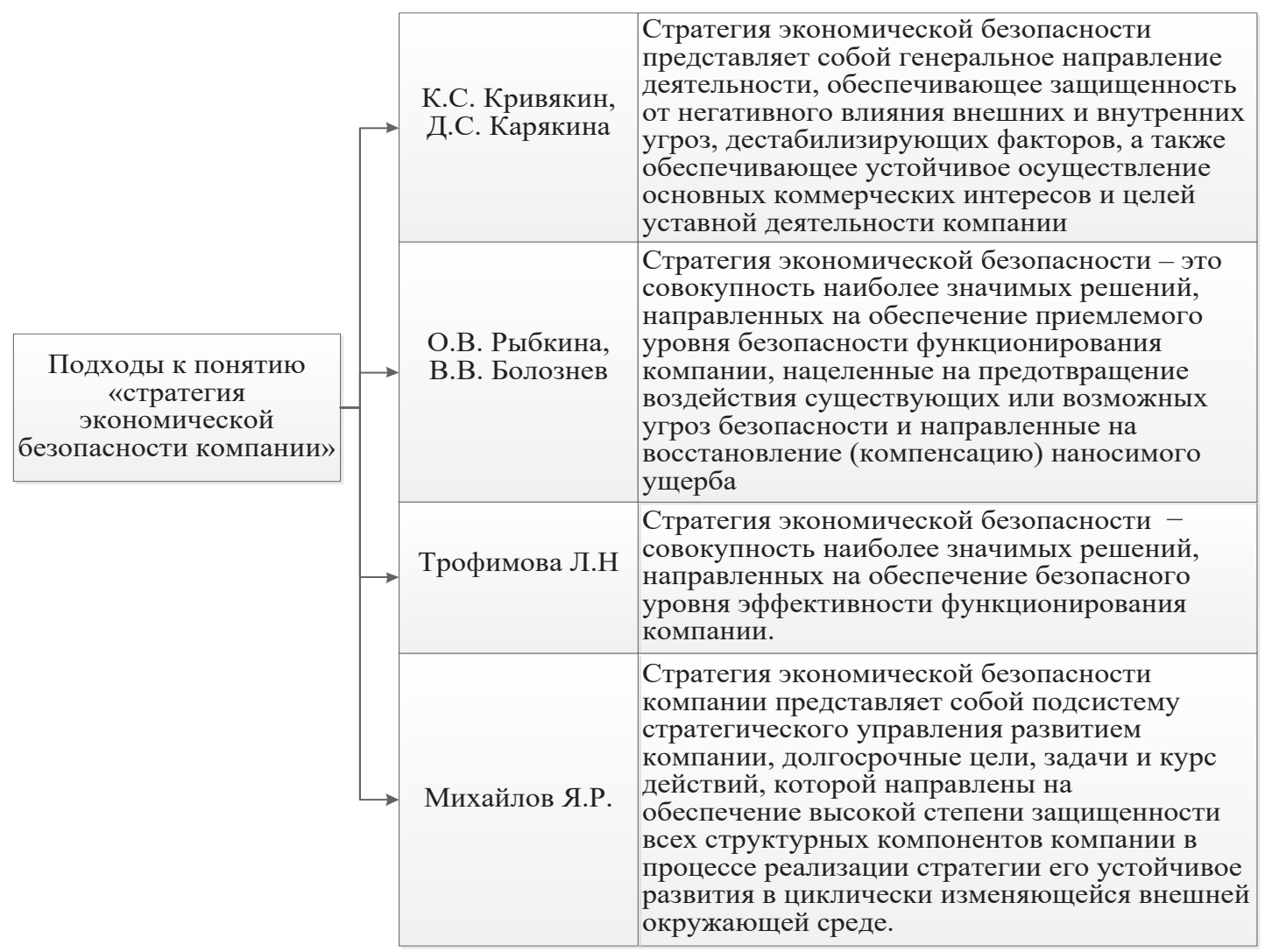

экономической безопасности любой современной компании имеет определенного рода структуру, которая включает в себя стратегию, выступающую фундаментальной основой развития компании.

В настоящее время, сформировалось несколько подходов к понятию «стратегия экономической безопасности компании», данные подходы представлены на Рисунке 4. 
Согласно проанализированным понятиям (рисунок 4), стратегия экономической безопасности компании выступает одним из базовых элементов обеспечения безопасности в целом, определяет направление деятельности и создает благоприятную среду для устойчивого развития и достижения поставленных компанией целей.

Стратегия экономической безопасности позволит управлять происходящими в компании процессами и контролировать возникновение угроз. Стратегия экономической безопасности компании должна учитывать, как общие угрозы, так и факторы, характерные для конкретной компании, например, мнение руководителей Министерств или других вышестоящих организаций, а также политическую конъюнктуру в конкретной стране и мире в целом.

Стратегия экономической безопасности должна быть разработана с акцентом на особенности рыночной деятельности, потенциальные и реальные угрозы, а также перспективы развития компании. В частности, стоит оценить состояние и развитие конкурентной рыночной среды, на которую ориентирована деятельность компании.

Стратегия экономической безопасности компании предполагает долговременные, наиболее значимые задачи и намерения руководства (менеджмента) компании, нацеленные на построение системы безопасности. Кроме того, стратегия экономической безопасности ориен- тирована на создание механизмов управления и взаимодействия с целью предотвращения различного рода угроз и рисков, а также созданию условий для динамичного развития компании.

При выстраивании стратегии экономической безопасности компании необходимо использовать комплексное рассмотрение взаимосвязей между отдельными направлениями развития компании, которое позволит определить и установить границы и содержание процессов, происходящих внутри самой стратегии.

Как правило, разработка стратегии экономической безопасности компании базируется на определенном алгоритме. Указанный алгоритм выработан на практике и подтвержден теоретическими аспектами. Суть указанного алгоритма формирования стратегии экономической безопасности компании представлена на рисунке 5.

Первый этап подразумевает анализ данных, полученных за прошлые отчетные периоды функционирования компании. В качестве основных целей финансово-экономического анализа в рамках формирования стратегии экономической безопасности могут быть определены следующие:

- сформировать общее представление о деятельности компании;

- определить специфику и потенциальные угрозы эффективному функционированию;

- выявить недочеты и ошибки прошлых периодов.

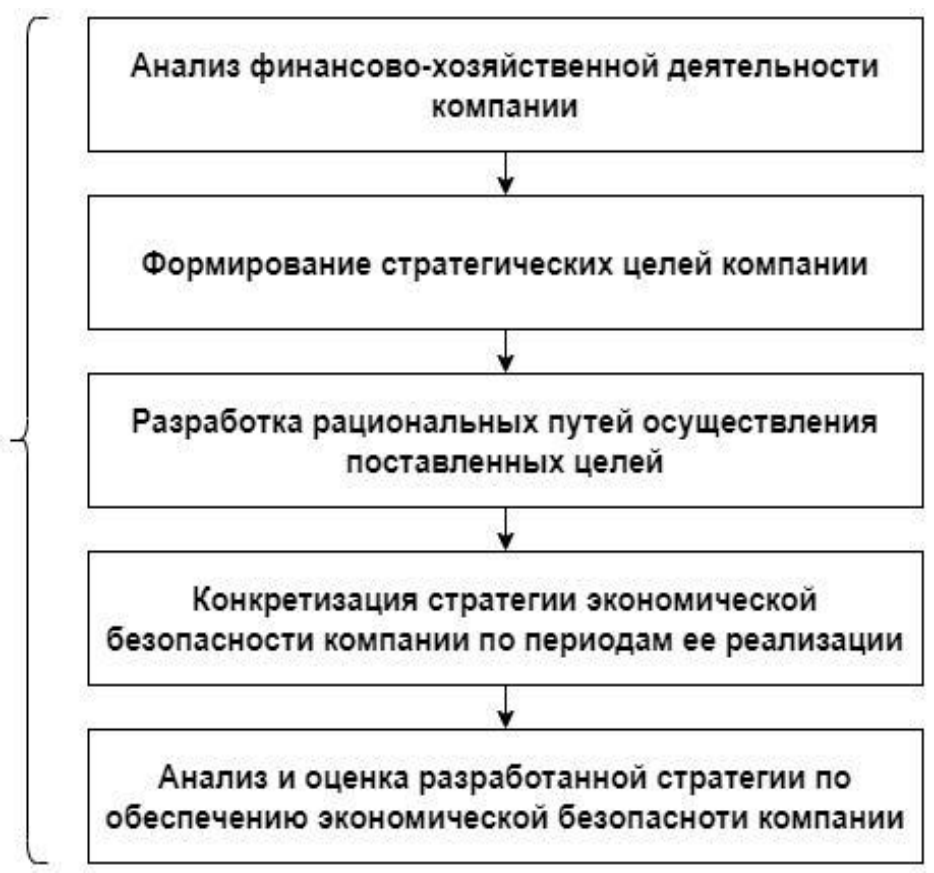

Рисунок 5. Алгоритм формирования стратегии экономической безопасности компании 
На втором этапе алгоритма происходит формирование целей и задач компании на долгосрочную перспективу, которые позволят обеспечить должный уровень экономической безопасности компании.

Одна из сложнейших задач компании - выбор наиболее эффективных путей реализации стратегических целей, потому принципиально контролировать все процессы компании, направленные их достижение.

Следующий этап характеризуется конкретизацией периодов реализации целей компании, а именно формируются последовательность и сроки достижения отдельных целей и задач компании.

Заключительный этап формирования стратегии экономической безопасности компании характеризуется ее оценкой на основе следующих критериев:

- соответствие сформированной стратегии экономической безопасности компании с общей стратегией ее экономического развития (анализ согласованность целей, этапов и направлений реализации данных стратегий);

- наличие внутреннего баланса стратегии (определение сопоставления отдельных целей и направлений деятельности, а также последовательность их выполнения);

- скорость адаптации стратегии экономической безопасности к быстроизменяющейся среде (оценка адаптации сформированной стратегии к прогнозируемым изменениям во внешней среде компании);
- результативности стратегии (основывается на оценке эффективности реализации разработанной стратегии).

В целом очевидно, что корректно разработанная и сформированная стратегия экономической безопасности копании позволит принимать наиболее эффективные управленческие решения, которые связанны постоянным развитием компании в быстроизменяющейся среде. Избежать значительных затрат материальных ресурсов, финансовых потерь, увеличить прибыль и инвестиционную привлекательность компании позволит эффективно выстроенная стратегия экономической безопасности.

Как уже неоднократно было отмечено выше, вопрос стратегии экономической безопасности компании остается малоизученным в теоретическом плане, при этом достаточно актуален и востребован с точки зрения практики функционирования реальных компаний.

Практические подходы к формированию стратегии экономической безопасности рассмотрим на примере российских лидирующих организаций нефтегазового сектора.

Нефтеперерабатывающая отрасль России существенно отстает в своем развитии от промышленно развитых стран мира (рисунок 6).

В настоящее время для нефтеперерабатывающей отрасли РФ характерно следующее:

- преобладание в корзине нефтеперерабатывающих заводов дешевых низкокачественных продуктов. У российских заводов сложность ниже среднемирового уровня и, как результат,

\section{Доказанные запасы нефти в 2018 г. млрд барр.}
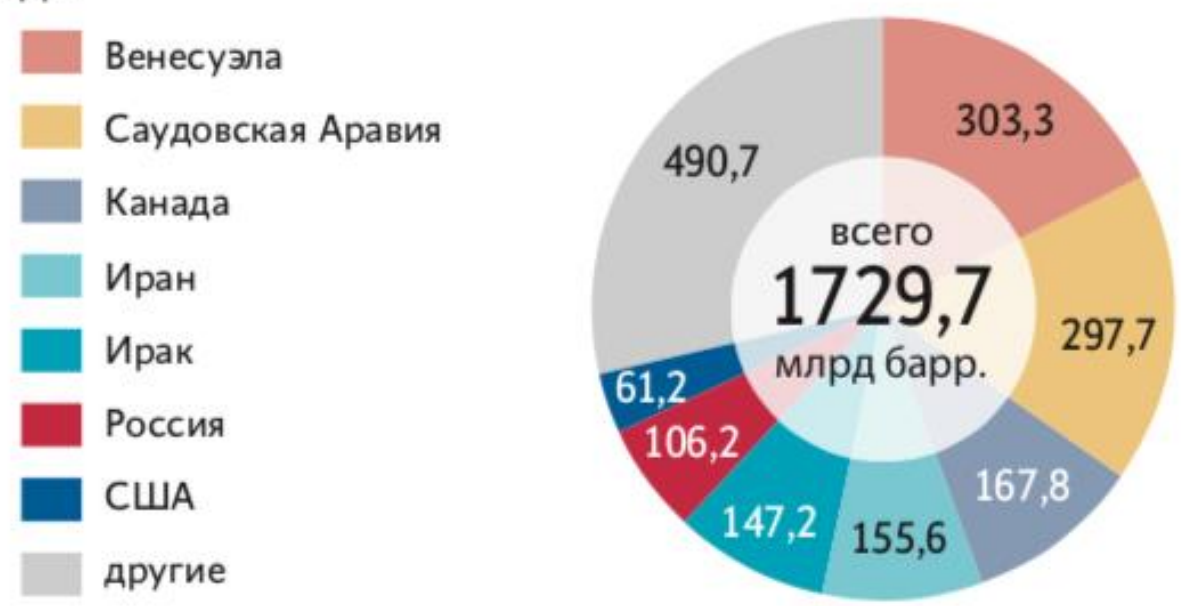

Рисунок 6. Запасы нефти на 2018 г. в разных странах 
ассортимент продуктов невысокого качества. По оценкам экспертов КИТФинанс, индекс сложности Нельсона (NCI) для российских нефтеперерабатывающих заводов в среднем составляет 4,9 по сравнению с 9,8 для США и среднемирового уровня в 6,1. В развитых странах работают сложные нефтеперерабатывающие заводы, имеющие в своем составе установки каталитического крегинга и гидрокрекинга, реформинга с непрерывной регенерацией, алкилирования, изомеризации нефтехимических процессов. В России же на многих НПЗ процесс атмосферновакуумной перегонки дополняется каталитическим реформингом для производства бензина и базовой гидроочисткой для производства дизельного топлива;

- российские нефтеперерабатывающие заводы в отличие от заводов развитых стран выпускают больше тяжелых дистиллятов, которые находятся на нижней границе ценового диапазона. В среднем в России доля мазута в объеме производства нефтеперерабатывающих заводов составляет около 30\%, а на заводах Западной Европы - менее 10\%. Между тем автомобильные бензин (АИ-95 и АИ-98 по российской квалификации) составляет незначительную долю в ассортименте отечественных нефтеперерабатывающих заводов: $2 \%$ против 16\% у западноевропейских;

- в отличие от развитых стран, в России маржа в нефтепереработке создается не благодаря продуктовой корзине, а за счет различия в экспортных пошлинах. Стоимость, создаваемая в добывающем сегменте, переносится в перерабатывающий сегмент через механизм экспортных пошлин, которые делают экспорт нефтепродуктов (в частности, экспорт мазута) более привлекательным, чем экспорт сырой нефти;

- налогообложение в России не только делает экспорт нефтепродуктов более привлекательным по сравнению с экспортом сырой нефти, но и поддерживает сбыт на зарубежные рынки основного нефтепродукта - мазута. Однако в недавнем времени Минфин выступил с предложением повысить налоги для нефтяных месторождений, которые пользуются льготами по НДПИ (налог на добычу полезных ископаемых) и экспортной пошлине, а также изменить параметры налога НДД (налог на добавленный доход), поскольку некоторые нефтяники используют льготы неэффективно;

- ключевым фактором, определяющим рен- табельность нефтеперерабатывающих заводов, являются транспортные расходы. Из-за больших расстояний в России расходы на транспортировку нефтепродуктов с заводов до морских портов являются высокими и составляют 30-35\% от валовой маржи нефтеперерабатывающих предприятий (НПЗ). Это контрастирует со сравнительно низкими расходами на транспортировку нефти с месторождений в морские порты (например, США) по системе магистральных нефтепроводов.

Описанные выше особенности нефтеперерабатывающей отрасли РФ закладывают определенные подходы к формированию стратегии экономической безопасности основных предприятий указанной отрасли.

Стратегия экономической безопасности, как было определено выше в рамках исследования сущности указанного понятия, должна быть нацелена на то, чтобы защитить компанию от дестабилизирующих факторов, а также создать благоприятный климат для развития и осуществления коммерческих интересов, целей и задач компании.

Важно отметить, что вопрос экономической безопасности нефтеперерабатывающих компаний является коммерческой тайной и выводы, представленные по тексту настоящей статьи, были сформированы исключительно на основе анализа публичных источников информации (в частности, интернет ресурсы, публичная отчетность и т.д.).

В качестве общей черты, свойственной всем средним и крупным предприятиям нефтегазового сектора, можно отметить, что принципиальным является понимание руководством указанных заводов необходимости качественной проработки стратегии и политики экономической безопасности: подход к данной задачи должен быть осознанным и исключать формальные элементы.

Наибольший интерес с практической точки зрения вызывает опыт формирования стратегии экономической безопасности компании «Лукойл». Алгоритм, разработанный ПАО «Лукойл», достаточно точно отражает суть стратегии экономической безопасности предприятий нефтегазового сектора РФ. Суть указанного алгоритма сводится к следующему: для начала специалисты по экономической безопасности формируют реестр угроз, которые потенциально могут нанести ощутимый ущерб деятель- 
ности компании. Далее, восприняв указанные угрозы, осуществляется анализ факторов их возникновения, чтобы заранее предотвратить источник их возникновения. На основе проведенного анализа разрабатываются, а затем реализуются действия корректирующего характера. По итогам, полученный результат оценивается, устраняются недостатки и предлагаются мероприятия, направленные на усовершенствования существующей стратегии экономической безопасности компании (во избежание повторения реализации выявленных угроз). О полученных результатах и соответствующих рекомендациях (мероприятиях) передается информация руководству. Затем стратегия экономической безопасности корректируется с целью повышения ее эффективности в будущих периодах.

Рассуждая о положительном опыте (практике) компании «Лукойл» в части разработки стратегии экономической безопасности необходимо учитывать тот факт, что все предприятия индивидуальны и простое копирование алгоритма формирования стратегии экономической безопасности не допустимо. Поэтому требуется проработка исследуемых в рамках настоящей статьи вопросов на базе не одного предприятия, а нескольких.

Анализ практики формирования стратегии экономической безопасности ведущих предприятий нефтегазового сектора позволит опередить ряд принципиальных моментов.

В первую очередь, формирование стратегии должно опираться на всестороннюю характеристику условий функционирования компании, прогнозирование и предотвращение рисков и угроз, наносящих вред интересам организации, цели и задачи стратегии экономической безопасности компании. Указанные элементы должны быть «уложены» в четко выраженную стратегию на долгосрочную перспективу, в которой будут сформулированы цели и задачи, а также механизм и план их реализации. При формировании стратегии стоит уделить внимание правовым, организационно-управленческим, расчетно-экономическим, аналитическим, цифровым и иным аспектам. На основе анализа создаются различные стратегии, направленные на прогнозирование, предотвращение и устранение угроз и их последствий, понижение уровня опасности до минимального уровня и т.д. Основу содержательной характеристики обеспечения экономической безопасности организации составляет взаимозависимость стратегии, рынка, а также системы мероприятий по предотвращению угроз.

В соответствии с вышеупомянутыми рекомендациями, результатами теоретикометодического анализа, а также анализу практического опыта компаний нефтегазового сектора, в части формирования стратегии экономической безопасности (в частности, ПАО «Лукойл»), можно смоделировать принципиальные основы алгоритма построения стратегии экономической безопасности нефтеперерабатывающей компании (рисунок 7).

Обсуждение и заключения Сформулированные выше этапы алгоритма формирования стратегии экономической безопасности компании (на основе анализа теоретико-методических основ и практического опыта компаний нефтеперерабатывающего сектора) базируются на анализе угроз.

На начальном этапе проектирования стратегии экономической безопасности предлагается в обязательном порядке проведение мониторинга и идентификации угроз, а также источников их возникновения. Далее, стоит обратить внимание, на выбор механизмов защиты / предотвращения угроз, а именно выбрать наиболее действенные методы, инструменты и средства защиты от опасностей внешней и внутренней среды. Поскольку предложенные этапы алгоритма построения стратегии экономической безопасности подразумевают постоянный мониторинг негативных воздействий, то завершающая стадия формирования стратегии, предполагает коррекцию проекта стратегии экономической безопасности с учетом полученных результатов на предыдущих этапов.

Разработанные (предложенные) в рамках настоящей статьи основы построения стратегии экономической безопасности компаний нефтегазового сектора позволят разрабатывать и принимать эффективные управленческие решения, связанные с повышением финансового результата компании в целом и достижением ею своих стратегических целей и задач. 
1 Определить цели, и задачи развития компании в нефтеперерабатывающей компании

\begin{tabular}{|c|c|}
\hline 2 & $\begin{array}{c}\text { Сделать учетно-аналитическое обоснование приблизительной стратегии обеспечения } \\
\text { безопасного развития нефтеперерабатывающей компании и оценка обеспеченности } \\
\text { ресурсами }\end{array}$ \\
\hline 3 & $\begin{array}{c}\text { Мониторинг состояния внешней среды в целях своевременного реагирования на } \\
\text { вызовы и угрозы экономической безопасности }\end{array}$ \\
\hline 4 & $\begin{array}{c}\text { Идентификация, оценка и анализ основных угроз, выявление их источников, выбор } \\
\text { инструментария и методов их нейтрализации }\end{array}$ \\
\hline 5 & $\begin{array}{c}\text { Комплексная реализация защитных мероприятий и мер по нейтрализации угроз, оценка } \\
\text { соответствия полученных результатов индикаторам экономической безопасности в } \\
\text { контексте вариации показателей ее стоимости }\end{array}$ \\
\hline 6 & $\begin{array}{c}\text { Факторный анализ динамики стоимости и разработка сценариев развития ситуации и } \\
\text { альтернативных вариантов решений }\end{array}$ \\
\hline 7 & $\begin{array}{c}\text { Сравнение, выбор и реализация оптимального варианта относительно базового } \\
\text { критерия оценивания }\end{array}$ \\
\hline 8 & $\begin{array}{c}\text { Контроль полученных результатов, итерационный мониторинг угроз и диагностика } \\
\text { уровня опасности }\end{array}$ \\
\hline 9 & $\begin{array}{c}\text { Корректировка стратегии нефтеперерабатывающей компании на основе полученных } \\
\text { результатов, принятие решений по достижению стратегических целей в повышении } \\
\text { конкурентоспособности компании }\end{array}$ \\
\hline
\end{tabular}

Рисунок 7. Рекомендуемые этапы алгоритма формирования стратегии экономической безопасности предприятий, работающих в сфере нефтепереработки

\section{Библиографический список}

\section{Книги, монографии, учебники}

Александров Г.А., Вякина И.В., СкворцоваГ.Г. Экономическая безопасность и инвестиционная привлекательность предприятий: характер взаимосвязи и проблема оценки // Экономические отношения. - 2019.Том 9. - № 3.- с. 2269-2284. - doi: 10.18334/ео.9.3.40915.

Васильев, Г.А. Экономическая безопасность предприятия в современных условиях / Г.А. Васильев, Э.А. Халикова // Экономика и современный менеджмент: теория и практика: сб. ст.по материалам VIII Междунар. науч.-практ. конф.- Новосибирск:СибАК, 2011.

Журавин С.Г., Замбржицкая Е.С., Абдулина Е.Г., Ананьева О.И. Современные аспекты понимания контроллинга // Актуальные проблемы современной науки, техники и образования. 2013. Т. 2. № 71. С. 347-351.

Зенченко С. В., Вартанова М.Л. Обеспечение финансовой безопасности региона в условиях санкций и экономического кризиса // Экономика, предпринимательство и право. - 2019. - Том 9. - № 4.- с. 257-270.doi: 10.18334/epp.9.4.41462.

Семенова А. А. Организация экономической безопасности хозяйствующего субъекта: учебно-методическое пособие / А. А. Семенова, М. Н. Кузина. М.: Русайнс, 2015.

Волкова Н.В., ГузиковаЛ.А., ДемиденкоД.С., Малевская-Малевич Е.Д., НиколоваЛ.В., Плотникова Е.В., Сорокожердвев К.Г., Кудрявцева Т.Ю., ЧачинаЕ.Г., Никоноров В.М., Тихомиров А.Ф., СтепанчукА.А., Пирогова O.E. - Финансовый менеджмент «Конспект лекций», Интернет-ресурс, URL: https://www.elibrary.ru/item. asp?id=36391017.

Иванов Ф.К., Феофилова Т. Ю.- Национальная система ПОД/ФТ: учебное пособие Санкт-Петербургский политехнический университет Петра Великого.-Санкт-Петербург: Политех-пресс, 2019. 


\section{Статьи из электронных журналов}

Баркатунов В. Ф. Стратегия экономической безопасности и проблемы развития предпринимательства в условиях современной России // Политика, экономика и инновации. 2018. № 3 (20). URL: https://cyberleninka. $\mathrm{ru} /$ article/n/strategiya-ekonomicheskoy-bezopasnosti-i-problemy-razvitiya-predprinimatelstva-v-usloviyahsovremennoy-rossii (дата обращения: 02.07.2020).

Бурмистрова А.А., Кондрашова И. С., Родионова Н. К. Государственная стратегия экономической безопасности РФ: цели, задачи, принципы // Социально-экономические явления и процессы. 2016. № 3. URL: https:// cyberleninka.ru/article/n/gosudarstvennaya-strategiya-ekonomicheskoy-bezopasnosti-rf-tseli-zadachi-printsipy (дата обращения: 02.07.2020).

Кононов В.Н., Замбржицкая Е.С., Дема Р.Р., Харченко М.В. Управление жизненными циклами промышленных технологий // Вестник Омского университета. Серия: Экономика. 2018. № 1 (61). С. $76-87$.

Кривякин К.С., КарякинаД.С. Основы разработки стратегии экономической безопасности предприятия // Экоминфо. 2017. № 4. URL: https://cyberleninka.ru/article/n/osnovy-razrabotkistrategii-ekonomicheskoybezopasnosti-predpriyatiya (дата обращения: 15.04.2020).

Кузнецова М. В. Оценка показателей инновационной деятельности и их использование в управлении экономической безопасностью // Вестник экономической безопасности. 2019. №3. URL: https://cyberleninka.ru/ article/n/otsenka-pokazateley-innovatsionnoy-deyatelnosti-i- ih-ispolzovanie-v-upravlenii-ekonomicheskoybezopasnostyu (дата обращения: 02.07.2020).

Махов М.В.Анализ основных подходов к определению понятия экономической безопасности предприятия // Проблемы экономики и менеджмента. 2016. № 5 (57). URL: https://cyberleninka.ru/article/n/analizosnovnyh-podhodov-k-opredeleniyuponyatiya-ekonomicheskoy-bezopasnosti-predpriyatiya (дата обращения: 20.04.2020).

Морозов С.И., Асмус О.В., Жигалова О. В. Превентивная система обеспечения экономической безопасности региона // Экономические отношения. - 2019. - Том 9. - № 3. - c. 1683-1696. - doi: 10.18334/eo.9.3.41060.

Омарова 3. К. Социально-экономическая безопасность внутреннего рынка России и методика ее комплексной оценки // Экономика и социум: современные модели развития. - 2019. - Том 9. - № 1.- c. 67-76. - doi: 10.18334/ecsoc.9.1.40538.

Перминов О.Г., Глущенко Н. В. - О системе экономической безопасности предприятий нефтегазовой отрасли // Проблемы экономики и юридической практики. 2016. № 6. URL: https://cyberleninka.ru/article/n/osisteme-ekonomicheskoy-bezopasnostipredpriyatiy-neftegazovoy-otrasli (дата обращения: 19.04.2020).

Сараджева О.В.Экономическая безопасность как основной компонент национальной безопасности России // Вестник Московского университета МВД России. 2015. № 4. URL: https://cyberleninka.ru/article/n/ ekonomicheskaya-bezopasnost-kak-osnovnoy-komponent-natsionalnoy-bezopasnosti-rossii (дата обращения: 02.07.2020).

Феофилова Т.Ю.Экономическая безопасность хозяйствующих субъектов в системе национальной безопасности Российской Федерации: проблемы и пути их решения. URL: https://www.elibrary.ru/item. asp?id=26158467 (дата обращения: 02.07.2020).

Феофилова Т.Ю.Проблемы теории экономической безопасности. URL: https://www.elibrary.ru/contents. asp?titleid=7603 (дата обращения: 02.07.2020).

Dubolazova Y.A. The system of balanced development of innovation enterprises, URL: https://scholar.google.ru/ citations?user=pct3ItQAAAAJ (дата обращения: 02.07.2020).

\section{Материалы конференций}

Замбржицкая Е. С., Васючкова Е.А. Место и роль инвестиционно-финансового потенциала в системе управления современным промышленным предприятием // В сборнике: Современная модель управления: проблемы и перспективы - материалы III Всероссийской научно-практической конференции. 2019. С. 12-16. Лесняк B. В., Селезнева Е. М. Сегментарное прогнозирование и анализ в системе управления экономической безопасностью организации // Сборник статей международной исследовательской организации «Сognitio» по материалам XXVIII международной научно-практической конференции «Актуальные проблемы науки XXI века», часть 1. М.: Изд-во Cognitio, 2017.-С. 66-71. 